\title{
Patient satisfaction with clinical laboratory services at Tikur Anbessa Specialized Hospital, Addis Ababa, Ethiopia
}

This article was published in the following Dove Press journal:

Patient Preference and Adherence

12 July 2017

Number of times this article has been viewed

\section{Rodas Getachew Abera \\ Boaz Arka Abota \\ Melese Hailu Legese \\ Abebe Edao Negesso}

Department of Medical Laboratory Sciences, School of Allied Health Sciences, College of Health Sciences, Addis Ababa University, Addis Ababa, Ethiopia
Correspondence: Rodas Getachew Abera Department of Medical Laboratory Sciences, School of Allied Health Sciences, College of Health Sciences, Addis Ababa University, PO Box 3427, Addis Ababa, Ethiopia

Tel +25 I 92 I 622607

Email rodas.getachew@yahoo.com
Background: Monitoring patient satisfaction is an important and useful quality improvement tool for clinical laboratories in particular and health care organizations in general. Thus, this study aimed to assess patient satisfaction toward clinical laboratory services at Tikur Anbessa Specialized Hospital (TASH), Addis Ababa, Ethiopia.

Methods: A hospital-based cross-sectional study was conducted and a convenient sampling technique was applied to recruit study participants. A total of 210 patients who had received laboratory services were included. A self-administered predesigned, pretested, structured questionnaire was used, and data were collected through face-to-face interviews. A 5-point Likert scale with 1 and 5 indicating the lowest and highest levels of satisfaction, respectively, was used and their weighted average was used to categorize the satisfaction level of the patients. Chi square test was used (taking $P \leq 0.05$ as the statistically significant level) to find out if any association existed between the level of satisfaction and different attributes. Data were analyzed using SPSS version 20.

Results: The overall level of patient satisfaction toward clinical laboratory services in this study was $59.7 \%$ with a response rate of $210(100 \%)$. The Likert scale results of patient satisfaction of the laboratory services revealed that the mean rating values ranged from $3.05( \pm 1.12)$ to $4.12( \pm 1.08)$ out of a possible 5. Among the different indicators, patients were highly satisfied with the cleanliness of facility $(82 \%)$, maintenance of privacy and confidentiality $(83.2 \%)$, and the cost of the laboratory service ( $86.5 \%$ ), while they were dissatisfied with the location of the laboratory $(56 \%)$, latrine accessibility and availability (58.4\%), and latrine cleanness and comfort (63.8\%).

Conclusion: The whole availability of requested tests, availability of place in blood drawing room to put personal things, and waiting time for specimen collection were found to have a statistically significant association with the overall satisfaction of patients toward clinical laboratory services. Therefore, these could be the possible determinants among others that account for the dissatisfaction of patients with clinical laboratory services.

Keywords: patient satisfaction, hospital services, quality of care, referral hospital, Tikur Anbessa Specialized Hospital, Ethiopia

\section{Introduction}

Patient satisfaction has been defined as the degree of congruency between a patient's expectations of ideal care and his/her perception of the real care(s) he receives. ${ }^{1} \mathrm{~A}$ component of effective health care services is the measurement of patient satisfaction. Patient satisfaction assists in the evaluation of health care services from the patients' point of view. It also facilitates the identification of problem areas and generates ideas for resolving these problems. Monitoring patient satisfaction is an important and useful quality improvement tool for clinical laboratories in particular and health 
care organizations in general. Most clinical laboratories in the USA are required to assess their customers' satisfaction in order to maintain their accreditations. ${ }^{2}$

Especially, in today's intensely competitive health care environment, it is not just a matter of choice that clinical laboratories need to satisfy the expectations of their customers. They do not even have to rely on or wait for somebody outside to carry out the patient satisfaction survey for them. Any laboratory should have a written policy focusing on customer's satisfaction and should periodically measure and evaluate their customer's satisfaction. ${ }^{3}$ First to fulfill the moral obligations expected from them, second in order to thrive for a better service and remain in competition with other hospitals, and last but not least, to get recognition and accreditation. $^{4}$

In the recent past, studies on patient satisfaction gained popularity and usefulness as it provides the chance to health care providers and managers to improve the services in the public health facilities. ${ }^{5}$

Patient satisfaction survey should not just be carried out for academic evaluation purposes only but for periodically aiming the bigger picture of better customer service. Measuring patient satisfaction plays an increasingly important role in the growing push toward health care provider accountability. Repeating studies at six monthly intervals is a useful managerial intervention aimed at delivering and maintaining quality health care. ${ }^{6}$

The health care service scenario in Ethiopia is expected to evolve into a more developed stage, the laboratory sector being the main focus. Considering $>70 \%$ of all medical decisions are based on laboratory results, more emphasis needs to be given on patient satisfaction as this is an important consideration for the assessment of the laboratory services.

In the face of increasing demand and resource constraints, the challenge that exists today is to reach the whole population with adequate health services and ensure their utilization. The problem with health care providers and programs in developing countries is that they have overwhelming emphasis on quantitative aspect of service delivered, which means that, in a quest to chase runaway targets, we neglect the concept of quality of care, which is also a right of clients. ${ }^{7}$ In providing health care services, the patients' satisfaction cannot be neglected, as it is important as much as the treatment and even the cure of the disease. ${ }^{8}$ Patients' perception is also an important factor in utilizing the available health care delivery services, which seems to have been largely ignored by health care managers in developing countries. ${ }^{9}$

Ethiopian hospital administration research is still in its infancy. Studies relating to patient behavior and satisfaction are infrequent. Only a few studies have attempted to evaluate patient satisfaction with the laboratory experience in Ethiopia. And in most cases, surveys for laboratory service are conducted, but authorities often fail to integrate the results into the continuous quality improvement and strategic planning processes. Moreover, most of laboratory management do not often act upon customer service feedback. ${ }^{3}$

The laboratory patient satisfaction studies that have been carried out in Ethiopia over the past 10 years have something in common; many, if not all, of the researchers based their study onto the regional state hospitals or rural areas with an exception of very few studies. Even those studies that have been made in Addis Ababa were restricted to only antiretroviral therapy monitoring laboratory services. Given the lack of adequate study on the matter, more studies need to be conducted periodically on the general laboratory services. Hence, our study attempts to assess the patient satisfaction of laboratory services received at Tikur Anbessa Specialized Hospital (TASH), Addis Ababa, Ethiopia.

\section{Materials and methods Study design, period, and area}

A hospital-based cross-sectional study was conducted from March to April 2016, at TASH, which is the biggest and busiest referral hospital located in Addis Ababa, the capital city of Ethiopia. It is positioned to serve patients from different parts of the country and is, in effect, the apex of the public health service hierarchy in Ethiopia.

\section{Sample size and data collection}

The required sample size for the patients was determined by using a single population formula considering the following assumptions: proportion of $87.6 \%$ (taken from a previous study made on a patient's laboratory perception at selected government hospitals in eastern Ethiopia); ${ }^{12}$ level of significance $=0.05$, margin of error $(d)=5 \%$ and a non respondent rate of $10 \%$. Therefore, 210 patients were included.

A total of 210 patients were enrolled in the study, and a convenience sampling technique was applied to recruit the study participants. Adding an estimated $10.0 \%$ for the nonresponse rate, a total of 210 patients made up the sample size, estimated based on an absolute precision of $5.0 \%$ with a $95 \%$ confidence level and $87.6 \%$ patient satisfaction.

Data were collected by face-to-face interviews using structured questionnaire. The questionnaire was initially prepared in English after reviewing relevant literatures and the finalized questionnaire was then translated into Amharic, the state language for administering purposes, and retranslated back into English to ensure its consistency. 
The questionnaire was standardized by a small scaled pilot test on 15 patients. It comprises 34 items which measure the seven core dimensions of patient satisfaction - location of the laboratory in the hospital, availability of laboratory staff on working hours, waiting time for specimen collection, satisfaction with cost of the laboratory services, relationship between patient and laboratory personnel, test results received on time as told/not missing, and maintaining privacy and confidentiality.

The questionnaire consisted of 5-point Likert scale items, with 1 and 5 indicating the lowest and highest levels of satisfaction, respectively. Patients indicated their level of satisfaction by selecting responses ranging from very dissatisfied $=1$, dissatisfied $=2$, neutral $=3$, satisfied $=4$, and very satisfied $=5$. Aside from satisfaction indicators, the questionnaire consisted of sociodemographic characteristics of the patients and different dimensions of the laboratory services.

All laboratory service users of both sexes who were willing to participate on the survey were interviewed after completing their laboratory examinations upon leaving the hospital. In order to maintain complete confidentiality, no names were recorded on the questionnaire.

As part of qualitative assessment, all interviewed patients were also asked if they had specific complaints or recommendations regarding their encounter in the laboratory at the end of their interview and recorded it on the comments section of the questionnaire.

\section{Data processing and analysis}

The surveyed questionnaires were collected, checked for its completeness, entered, and analyzed by using the SPSS statistical package, version 20. Descriptive statistics were performed on the sociodemographic data, and Pearson's chi-square test was used to examine the relationship between satisfaction with laboratory services, gender, age, educational status, and other different attributes.

A 5-point Likert scale rating of very dissatisfied (1 point), dissatisfied ( 2 points), neutral (3 points), satisfied (4 points), and very satisfied ( 5 points) was used. To calculate the level of patient satisfaction on different laboratory services, very dissatisfied and dissatisfied were considered as dissatisfied and satisfied and very satisfied were considered as satisfied. Patients with neutral rating responses were excluded. The percentage satisfaction or dissatisfaction was calculated by dividing the number of satisfied or dissatisfied responses by the total number of respondents excluding neutral response ratings, respectively.

The overall rate of satisfaction by Likert scale was calculated as (number of very satisfied rating $\times 5)+($ number of satisfied rating $\times 4)+($ number of neutral rating $\times 3)+($ number of dissatisfied rating $\times 2)+($ number of very dissatisfied rating $\times 1$ ) divided by the total number of ratings (1-5) for the specific laboratory service. Association of the variables with level of satisfactions on laboratory services was checked by using chi-square test. $P$-value $<0.05$ was considered as statistically significant.

\section{Ethical considerations}

Ethical clearance was obtained from the Departmental Research and Ethics Review Committee (DRERC) of the School of Medical Laboratory Sciences; Addis Ababa University. In addition to DRERC, a permission letter was obtained from TASH. The objectives of the study were explained to the study participants and written informed consent was obtained before interviewing each participant. All the information obtained from the study participants was kept confidential.

\section{Results \\ Sociodemographic characteristics of the participants}

A total of 210 patients were enrolled in the study and the response rate was $100 \%$. The majority $77(36.7 \%)$ of the participants lie within the age group of 28-37 years, 47 (22.4\%) of the participants lie in the age group 38-47 years followed by $42(20 \%)$ people in the age group 18-27 years, and 32 $(15.2 \%)$ in the age group $48-57$ years. The smaller group (12 [5.7\%]) consists of those aged $\geq 58$ years (Figure 1).

Of the 210 respondents, 120 (57.1\%) were male. Majority of the respondents (93 [44.3\%]) were married. About 88 (41.9\%) of them were Orthodox Christians and 72 (34.3\%) belong to the Amhara ethnic group. During the present survey, 82 (39\%) of the respondents have attained secondary school and $62(29.5 \%)$ have attended at college level. About 145 (69\%) of the respondents live in Addis Ababa, while the rest 65 (31\%) were out of Addis Ababa. Half of the respondents belong to the working class (Table 1).

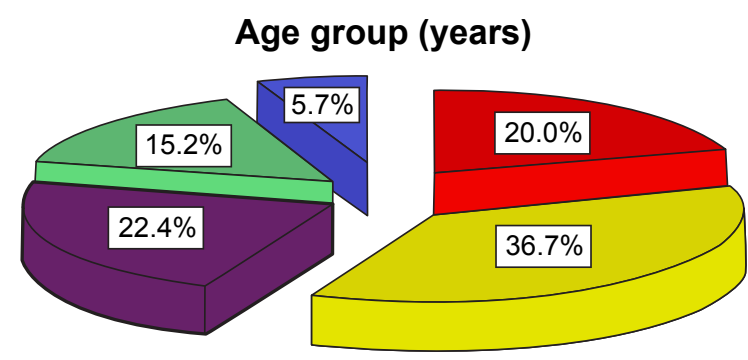

18-27 $\square$ 28-37 $\square$ 38-47 $\square$ 48-57 $\square$ 258 years

Figure I Distribution of respondents to age groups. 
Table I Sociodemographic characteristics of respondents on patient satisfaction with clinical laboratory services received at TASH, Addis Ababa, March to April, $2016(n=210)$

\begin{tabular}{|c|c|c|}
\hline Variable & Frequency & Percentage \\
\hline \multicolumn{3}{|l|}{ Gender } \\
\hline Male & 120 & 57.1 \\
\hline Female & 90 & 42.9 \\
\hline \multicolumn{3}{|l|}{ Age group (years) } \\
\hline $18-27$ & 42 & 20 \\
\hline $28-37$ & 77 & 36.7 \\
\hline $38-47$ & 47 & 22.4 \\
\hline $48-57$ & 32 & 15.2 \\
\hline$\geq 58$ & 12 & 5.7 \\
\hline \multicolumn{3}{|l|}{ Marital status } \\
\hline Single & 58 & 27.6 \\
\hline Married & 93 & 44.3 \\
\hline Divorced & 20 & 10.5 \\
\hline Widowed & 37 & 17.6 \\
\hline \multicolumn{3}{|l|}{ Ethnicity } \\
\hline Oromo & 52 & 24.8 \\
\hline Amhara & 72 & 34.3 \\
\hline Tigray & 42 & 20 \\
\hline Gurage & 27 & 12.9 \\
\hline Other* & 17 & 8.1 \\
\hline \multicolumn{3}{|l|}{ Religion } \\
\hline Orthodox & 88 & 41.9 \\
\hline Muslim & 42 & 20 \\
\hline Protestant & 58 & 27.6 \\
\hline Catholic & 17 & 8.1 \\
\hline Other** & 5 & 2.4 \\
\hline \multicolumn{3}{|l|}{ Place of residence } \\
\hline Addis Ababa & 145 & 69 \\
\hline Outside Addis Ababa & 65 & 31 \\
\hline \multicolumn{3}{|l|}{ Education level } \\
\hline Illiterate & 17 & 8.1 \\
\hline Read and write & 12 & 5.7 \\
\hline Primary education & 37 & 17.6 \\
\hline Secondary education & 82 & 39 \\
\hline College/university & 62 & 29.5 \\
\hline \multicolumn{3}{|l|}{ Occupation } \\
\hline Working class & 102 & 48.6 \\
\hline Unemployed & 22 & 10.5 \\
\hline Student & 42 & 20 \\
\hline Housewife & 32 & 15.2 \\
\hline Retired & 12 & 5.7 \\
\hline
\end{tabular}

Notes: *Wolayita, Hadiya, and Silte; **jehovah's witness.

Abbreviation: TASH, Tikur Anbessa Specialized Hospital.

In Likert scale, the overall mean rate of satisfaction of patients by laboratory services in TASH was 3.21. The mean rate of satisfaction for different aspects of laboratory services ranged from 3.05 to 4.12 . The lowest mean rating of satisfaction was given for the location of the laboratory in the hospital and latrine accessibility and availability with mean ratings of 3.05 and 3.14, respectively. Higher mean rating of satisfaction was obtained for the cleanliness of facility (3.84), ability of the laboratory personnel to answer questions (3.91), maintaining privacy and confidentiality (3.88), and cost of the laboratory service (4.12) as indicated in Table 2.

There was no statistically significant association between gender and overall satisfaction $(P=0.315)$. But still, a slight difference can be seen between the two sexes from the graph below even though it was not strong enough to cause any significant association. Women seem to be relatively less satisfied than men do (Figure 2).

About 56 (46.7\%) of the male study subjects from the total population, 120, were satisfied with the services provided by TASH. Those who have not developed bruise after phlebotomy procedures, 70 (45.2\%), were also satisfied. About 71 (54.6\%) people whose prescribed laboratory investigations were performed at TASH felt the same. There were significant associations between sociodemographic characteristics and satisfaction of respondents on the laboratory services given at TASH except for gender and problem of overcrowding (Table 3).

\section{Discussion}

This study has revealed that the overall satisfaction level of the patients with clinical laboratory services rendered at TASH in Addis Ababa was 59.7\%, and this is lower than reports from other studies conducted in Jimma (77\%), Addis Ababa (85.5\%), Eastern Ethiopia (87.6\%), and Southern Ethiopia (90.8\%). ${ }^{3,10-12}$ The possible reason for lower patient satisfaction in this study could be the use of a relatively lower number of sample size and the use of single question's response to generate the score of overall patient satisfaction though it was intended for patients to give their general thoughts on the hospital's laboratory services without being necessarily restricted to only the survey questionnaires. However, the studies conducted in Addis Ababa and southern Ethiopia were only about patient satisfaction with antiretroviral therapy monitoring laboratory services, which is the focus of attention for government and many donors.

However, our finding was higher than the findings in Addis Ababa, Eastern Ethiopia Hospitals, and Jimma Hospital with patient satisfaction levels of $51.7 \%, 54.1 \%$, and $57.1 \%$, respectively. ${ }^{10,13,14}$

Just above three-fourths of the total respondents (160 [76.2\%]) said overcrowding was a problem around sample collection units and result dispatching area. An overwhelming majority (81\%) said there was no place in the blood drawing room to put personal things. The great majority (155 [73.8\%]) had only a single needle stick attempt when 


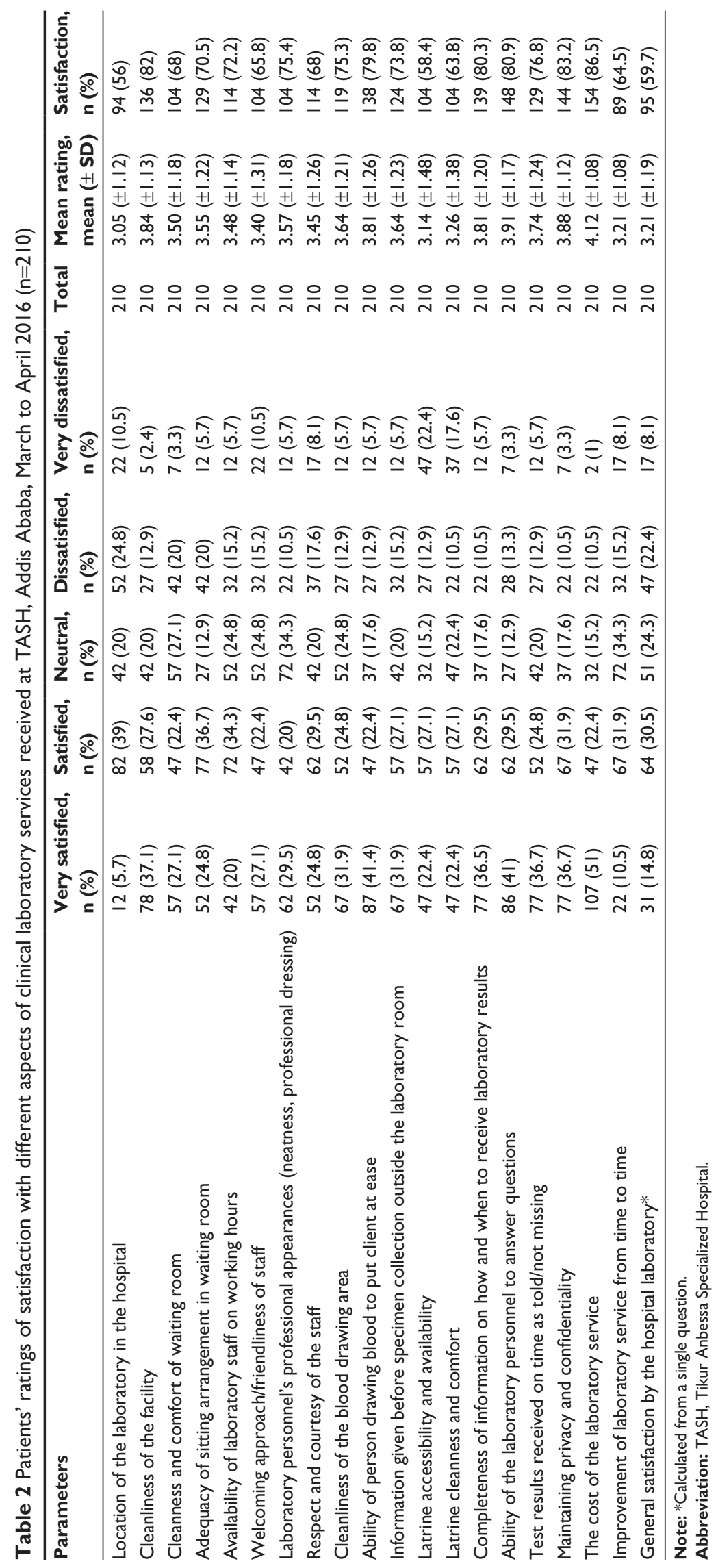




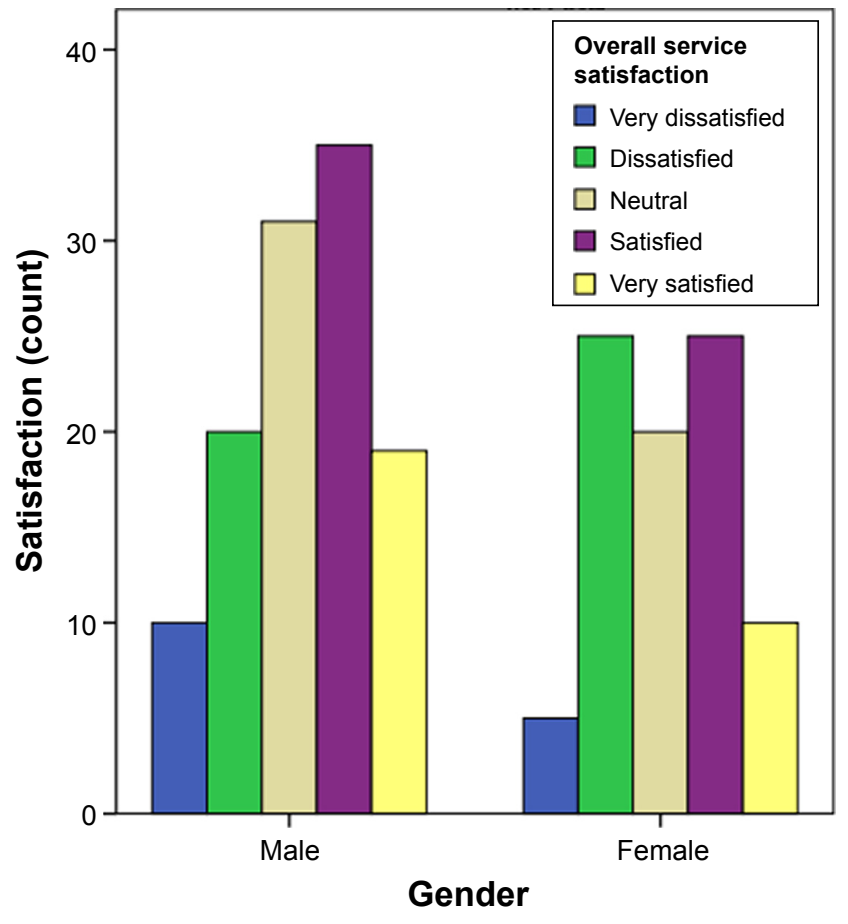

Figure 2 Overall satisfaction with respect to gender. drawn blood and did not develop bruise after the phlebotomy procedure. About 95 (45.2\%) patients waited $<30$ minutes for specimen collection, 80 (38.1\%) had to wait for 30 minutes up to 1 hour, and the remaining 35 (16.7\%) waited 1-2 hours. About 130 (61.9\%) of the patients interviewed at the laboratory reported that all of their prescribed laboratory investigations were performed at TASH. The remaining patients said that they had to go elsewhere for some of the tests.

The level of satisfaction of the patients was not statistically different by place of residence and gender. However, there was a statistical difference with respect to age, educational level, waiting time for specimen collection, and availability of place in the blood drawing room to put personal things.

Higher rate of patient satisfaction was on the cleanliness of facility, cost of the laboratory, and completeness of information on how and when to receive laboratory results. Lower rate was obtained on location of the laboratory in the hospital and latrine accessibility and availability.

Table 3 Comparisons of the overall level of patient satisfaction with clinical laboratory services provided at TASH and sociodemographic factors, March to April, $2016(\mathrm{n}=210)$

\begin{tabular}{|c|c|c|c|c|c|}
\hline \multirow[t]{2}{*}{ Variables } & \multicolumn{2}{|c|}{ Satisfaction, n (\%) } & \multicolumn{3}{|c|}{ Chi-square value } \\
\hline & Satisfied & Dissatisfied & $d f$ & $x^{2}$ & $P$-value \\
\hline \multicolumn{5}{|l|}{ Gender } & 0.315 \\
\hline Male & $56(46.7)$ & $33(27.5)$ & 4 & $4.74 I$ & \\
\hline Female & $39(43.3)$ & $31(34.4)$ & & & \\
\hline \multicolumn{5}{|l|}{ Age (years) } & 0.000 \\
\hline $18-27$ & $16(38.1)$ & II (26.19) & & & \\
\hline $28-37$ & $43(55.8)$ & $16(20.8)$ & & & \\
\hline $38-47$ & $23(48.9)$ & $10(21.3)$ & 16 & 55.549 & \\
\hline $48-57$ & 7 (21.9) & $21(65.3)$ & & & \\
\hline$\geq 58$ & $6(50)$ & $6(50)$ & & & \\
\hline \multicolumn{5}{|l|}{ Place of residence } & 0.023 \\
\hline Addis Ababa & $65(44.83)$ & $38(26.2)$ & 4 & 11.348 & \\
\hline Outside Addis Ababa & $30(46.2)$ & $26(40)$ & & & \\
\hline \multicolumn{5}{|l|}{ Education level } & 0.000 \\
\hline Illiterate & I (5.9) & $7(4 \mid .2)$ & & & \\
\hline Read and write & $2(16.7)$ & $7(58.3)$ & 16 & 84.120 & \\
\hline Primary education & $18(48.6)$ & $5(13.5)$ & & & \\
\hline Secondary education & $41(50)$ & $25(30.5)$ & & & \\
\hline College/university & $33(53.2)$ & $20(32.3)$ & & & \\
\hline \multicolumn{5}{|l|}{ Occupation } & 0.000 \\
\hline Working class & $39(38.2)$ & $42(4 \mid .2)$ & & & \\
\hline Unemployed & II (50) & $6(27.3)$ & & & \\
\hline Student & $23(54.8)$ & $5(11.9)$ & 16 & 75.157 & \\
\hline Housewife & $16(50)$ & $5(15.6)$ & & & \\
\hline Retired & $6(50)$ & $6(50)$ & & & \\
\hline \multicolumn{5}{|c|}{ Waiting time for specimen collection } & 0.000 \\
\hline$<30$ minutes & $40(42.1)$ & $32(33.7)$ & 8 & 829.197 & \\
\hline 30 minutes $-I$ hour & $40(50)$ & $27(33.75)$ & & & \\
\hline I-2 hours & $15(42.9)$ & $5(14.3)$ & & & \\
\hline
\end{tabular}


Table 3 (Continued)

\begin{tabular}{|c|c|c|c|c|c|}
\hline \multirow[t]{2}{*}{ Variables } & \multicolumn{2}{|c|}{ Satisfaction, n (\%) } & \multicolumn{3}{|c|}{ Chi-square value } \\
\hline & Satisfied & Dissatisfied & $d f$ & $x^{2}$ & $P$-value \\
\hline \multicolumn{5}{|c|}{ Problem of overcrowding } & 0.000 \\
\hline Yes & $76(47.5)$ & $47(29.4)$ & 4 & 46.563 & \\
\hline No & $19(38)$ & $17(34)$ & & & \\
\hline \multicolumn{5}{|c|}{ Number of needle stick attempts } & 0.000 \\
\hline One & $70(45.2)$ & $57(36.8)$ & 8 & 46.563 & \\
\hline Two & $23(57.5)$ & $7(17.5)$ & & & \\
\hline Three & $2(13.3)$ & $0(0)$ & & & \\
\hline \multicolumn{5}{|c|}{ Bruise development after phlebotomy procedures } & 0.000 \\
\hline Yes & $25(45.5)$ & $7(12.7)$ & 4 & 21.554 & \\
\hline No & $70(45.2)$ & $57(36.8)$ & & & \\
\hline \multicolumn{5}{|c|}{ Availability of place in the blood drawing room to put personal things } & 0.000 \\
\hline Yes & $31(77.5)$ & $\mathrm{I}(2.5)$ & 4 & 25.099 & \\
\hline No & $64(37.6)$ & $63(37.1)$ & & & \\
\hline \multicolumn{5}{|c|}{ Availability of requested laboratory tests } & 0.000 \\
\hline Yes all & $71(54.6)$ & $22(16.9)$ & 4 & 41.39 & \\
\hline Yes some only & $24(30)$ & $42(52.5)$ & & & \\
\hline
\end{tabular}

Note: $P$-value of $<0.05$ is significant.

Abbreviations: TASH, Tikur Anbessa Specialized Hospital; $d f$, degrees of freedom.

It should be taken into consideration that the study was conducted a few months before the hospital laboratory made some changes and improvements which might influence the findings of the current study, like, for instance, the adequacy of sitting arrangement in waiting room, changes with the location of the laboratory, and inclusion of some of the tests which previously were not available. These were some of the factors that the study participants showed dissatisfaction with. Therefore, more studies should be conducted regularly to improve service.

\section{Strength and limitations}

In this study, a relatively high number of indicators were employed to determine the overall patient satisfaction toward clinical laboratory services (it has 19 indicators).

However, the study did not assess the association between satisfactions toward pre-laboratory services and satisfaction toward clinical laboratory services. In addition, the sample size used is not that large enough to clearly demonstrate significant associations between sociodemographic characteristics and level of patient satisfaction.

\section{Recommendations}

The overall recommendation is that TASH should strive to maintain the high standard it has in order to keep the patients satisfied with the services they receive. As a national referral hospital, TASH is the final destination for most patients. Very few are referred to hospitals outside the country. TASH is equipped to provide the best medical care and has the most highly trained health professionals to provide it.
The patients who come to TASH should be able to experience it as such.

The hospital administrators and laboratory chiefs should work on the enhancement of laboratory services. Hospital administration needs to work with laboratory units in designing laboratory infrastructure. It should be accessible for the disabled and elderly.

A specific recommendation relates to the need to encourage the staff to treat patients with courtesy and respect in line with the Health Sector Reforms and patient-centered quality assurance. Allocate adequate man power to avoid delays and overcrowding. Last but not least, a concerted effort to improve the cleanliness and accessibility of the latrines is needed.

\section{Acknowledgments}

We express our deepest gratitude to all the study participants and Addis Ababa University, School of Medical Laboratory Science, Ethiopia. Our thanks also extend to TASH and Departmental Research and Ethics Review Committee (DRERC) of School of Medical Laboratory Sciences, Addis Ababa University, for giving the ethical clearance.

\section{Author contributions}

RGA designed the study, collected, analyzed, interpreted the data and drafted the manuscript. BAA participated in data collection, designing of the study and write up of the proposal. MHL and AEN contributed significantly in advising, editing, reviewing of both the proposal and manuscript. All authors contributed toward data analysis, drafting and 
revising the paper and agree to be accountable for all aspects of the work.

\section{Disclosure}

The authors report no conflicts of interest in this work.

\section{References}

1. Qadri SS, Pathak R, Singh M, Ahluwalia SK, Saini S, Garg PK. An assessment of patients satisfaction with services obtained from a tertiary care hospital in rural Haryana. Intern J Collabo Res Internal Med Pub Health. 2012;4(8):1524-1537.

2. Georgieva E, Tsankova G, Kaludova V, Ermenlieva N. Patients' satisfaction with laboratory services at selected medical diagnostic laboratories in Varna. J IMAB. 2014;20(2):500-501.

3. Belay M, Abrar S, Bekele D, Daka D, Derbe M, Birhaneselassie M. HIV/AIDS patients' satisfaction on ART laboratory service in selected governmental hospitals, Sidamma Zone, Southern Ethiopia. Sci J Pub Health. 2013;1(2):85-90.

4. Raheem AR, Nawaz A, Fouzia N, Imamuddin K. Patients' satisfaction and quality health services: an investigation from private hospitals of Karachi, Pakistan. Res J Recent Sci. 2014;3(7):34-38.

5. Sodani PR, Kumar RK, Srivastava J, Sharma L. Measuring patient satisfaction: a case study to improve the quality of care at public health facilities. Indian J Community Med. 2010;35(1):52-56.
6. Dawar R. Patient satisfaction of phlebotomy services in a tertiary care hospital. Int J Curr Res Aca Rev. 2015;3(6):35-38.

7. Chattopadhyay A, Saha T, Karmakar P, Sengupta P, Boral K, Yasmin S. Patient satisfaction evaluation in CGHS dispensaries in Kolkata, India. J Dent Med Sci. 2013;6(4):13-19.

8. Piang L, Tiwari V, Nair K, Raj S, Kaur H, Gandotra R. Patient's satisfaction with quality of services providers at the tertiary care cancer hospitals in India. Indian J Prev Soc Med. 2012;43(4):396-404.

9. Bogale A, Kassa H, Ali J. Patients' perception and satisfaction on quality of laboratory malaria diagnostic service in Amhara Regional State, North West Ethiopia. Malar J. 2015;14:241.

10. Oljira L, Gebree-Selassie S. Satisfaction with outpatient health services at Jimma Hospital, Southwest Ethiopia. Ethiopia J Health Dev. 2001; 15(3):179-184.

11. Tedla M, Bineyam T. Patients satisfaction with laboratory services at antiretroviral therapy clinics in public hospitals, Addis Ababa, Ethiopia. BMC Res Notes. 2012;5:184.

12. Teklemariam Z, Mekonnen A, Kedir H, Kabew G. Clients and clinician satisfaction with laboratory services at selected government hospitals in eastern Ethiopia. BMC Res Notes. 2013;6:15.

13. Tesfaye T. Assessments of patients' satisfaction towards clinical laboratory services received at uniformed service hospitals in Addis Ababa, Ethiopia. [Online]; 2016. Available from: http://etd.aau.edu.et/ handle/123456789/5580. Accessed February 1, 2016.

14. Birna A. The quality of hospital services in eastern Ethiopia: patient's perspective. Ethiop J Health Dev. 2006;20(3):199-200.
Patient Preference and Adherence

\section{Publish your work in this journal}

Patient Preference and Adherence is an international, peer-reviewed, open access journal that focuses on the growing importance of patient preference and adherence throughout the therapeutic continuum. Patient satisfaction, acceptability, quality of life, compliance, persistence and their role in developing new therapeutic modalities and compounds to optimize

\section{Dovepress}

clinical outcomes for existing disease states are major areas of interest for the journal. This journal has been accepted for indexing on PubMed Central. The manuscript management system is completely online and includes a very quick and fair peer-review system, which is all easy to use. Visit http://www dovepress.com/testimonials.php to read real quotes from published authors. 